\title{
Frequency and Outcomes of Anastomotic Leak in Gastrointestinal Surgery at Public Sector Hospital
}

\author{
Gulshan Ali Memon, ${ }^{1}$ Habib-ur-Rehman, ${ }^{2}$ Syed Kashif Ali Shah, ${ }^{3}$ Rafiq Ahmed Sahito, ${ }^{4}$ Shahnawaz \\ Leghari, ${ }^{5}$ Shahida Baloch ${ }^{6}$
}

\section{Abstract}

Objective: The objective of this study was to find out frequency of anastomotic leak at a hospital and deplore the morbidities, duration of hospital stay.

Methods: A total of 102 patients of both genders from $18-60$ years in age underwent for bowel resection and anastomosis through laparotomy incision at surgical unit one of People's University of Medical \& Health Sciences, Nawabshah, from January 2013 to December 2016 were enrolled in this cross-sectional study. Every patient received appropriate antibiotics for duration according to need post-operatively. Follow-up was every fortnightly for four months to evalu-

\footnotetext{
${ }^{1}$ Professor and Dean Surgery and Allied

Department of General Surgery, PUMHS, Nawabshah.

${ }^{2}$ Assistant Professor

Department of General Surgery, PUMHS, Nawabshah.

${ }^{3}$ Senior Registrar

Department of General Surgery, PUMHS, Nawabshah.

${ }^{4}$ Associate Professor

Department of General Surgery, PUMHS, Nawabshah.

${ }^{5}$ Postgraduate Trainee

Department of General Surgery, PUMHS, Nawabshah.

${ }^{6}$ Postgraduate Trainee

Department of General Surgery, PUMHS, Nawabshah.
}

Date of Submission: 20-03-2017

Date of ${ }^{\text {st }}$ Revision Received: 06-04-2017

Date of Acceptance for Publication: 24-04-2017

Conflict of Interest: None

Funding Source: None

\section{Contribution}

All Authors have contributed in Study Design, Data Collection, Data Analysis, Data Interpretation, Manuscript Writing and Approval. ate the primary outcome as prevalence of leak and secondary outcome as morbidities, length of hospital stay incisional hernia and mortality.

Results: The results showed that, out of 102 patients underwent open primary hand sewn gastro intestinal anastomosis, $16(15.68 \%)$ were found with anastomotic leak. Among these 16 patients having anatomic leak, $11(11 \%)$ were male \& $5(5 \%)$ were female. While, mortality occurred in $05(5 \% \%)$ patients.

Conclusions: Anastomotic leak following gastrointestinal anastomosis is less complication in this study. Further studies are requested with large data and more follow-ups to ensure the findings of this study at national level.

Keywords: Abdominal surgery, abdominal trauma, tuberculosis, anastomotic leak, conventional surgery.

\section{Introduction}

Intestinal anastomosis is surgical procedure to restore bowel continuity after removal of diseased or traumatized avascular bowel. ${ }^{1}$ The surgical wisdom has remained very much attentive with patient's outcomes and has developed various techniques with understanding of risk factors to obviate the most dreadful post-operative complication of gastrointestinal anastomotic leak, ${ }^{2}$ but it still remains a major cause of morbidity, mortality, re-operation and prolonged duration of hospitalization. $^{3-6}$ Various rate of anastomotic leaks noted in literature by researchers are $(8-41 \%$ (4) in rectum, $(3-29 \%(5-6)$ in colon, $(1-3 \%(7-8)$ in small intestine, $(1-9 \%(12-14)$ in stomach $(10-16 \%$ $(7-9)$ in bile ducts and $(2-16 \%$ (15) in esophagus. The mechanism concerning anastomotic leaks is still deceptive and elusive, ${ }^{7}$ Therefore most effective surgical techniques remains under considerable debate, but 
surgeons are all too familiar that generally outcome of surgical anastomosis depends upon certain critical factors like, the state of the health of the patient, BMI, American Society of Anaesthesiologist (ASA)score, sepsis, site, nature and volume of leak. ${ }^{8,9}$ The logical steps for the treatment in gastro intestinal anastomotic leaks are: re-operation with copious peritoneal wash and fecal diversion, drainage of collection, nutritional support, prevention of further contamination, infection and restoration of the continuity of gut. ${ }^{10,11}$ There are no standard guide lines of treatment to follow, hence the management and prevention of this complications becomes difficult and variable. ${ }^{12}$ So, anastomotic leak puts significant burden on the health care system and patients, beside the devastating clinical outcomes. ${ }^{13}$ This confronting challenge of anastomotic leak put the quest to identify the factors that could improve outcomes in resource limited hospitals, where a hand sewn anastomosis is still a common practice. The aims of our study were to find out frequency and outcomes of anastomotic leak at our hospital.

\section{Methods}

A total of 102 patients of both genders from 18-60 years in age, underwent for bowel resection and anastomosis through laparotomy incision at surgical unit one of People's University of Medical \& Health Sciences, Nawabshah, from January 2013 to December 2016 were enrolled in this cross-sectional study after having informed consent to participate as per described policy. The surgeries considered for inclusion were hand sewn entero-enteric anastomosis, colectomy and hemicolectomy. Patients below 18 years of age, patients using corticosteroids, underwent simple stoma closure, protective anastomosis by a proximal diversion or have transferred from other hospitals with leak, abscess or fistula were excluded from this study. Patients characteristics viz, sex, age, BMI, ASA score, length of hospital stay and surgical anastomotic types (ileo-ileal, iliocolic, colo-colic, colo-rectal) with relevant under lying cause/disease were recorded.

Every patient received appropriate antibiotics for duration according to need post-operatively. Patients were visited daily during their hospitalization and diets were allowed from liquids to regular on clinical assessments. Drains were removed when the output was less than $20 \mathrm{ml}$ per day. Post-operative complications were recorded by registrars and residents involved in this study.
Anastomotic leak was defined as an extra-luminal leakage of gastric or intestinal fluid from newly intervened gastro-intestinal anastomosis clinically presenting with post-operative fistula, abscess or air leak confirmed either by contrast-enhanced CT-scan or relaparotomy findings. The further intervention for fecal diversion decided on the clinical condition of patient supported by lab investigations was also recorded. Patients were discharged, when the condition was satisfactory. Follow-up was every fortnightly for four months.

A follow-up data form was completed at the follow-up in ward office to record the frequency of anastomotic leak, re-admission or complication after initial discharge. The recorded complications were reviewed by a senior surgeon of surgical unit one to evaluate the primary outcome as prevalence of leak and secondary outcome as morbidities, length of hospital stay incisional hernia and mortality.

Data analyzed on SPSS version 20. Descriptive analysis including patient baseline demographic, clinical features and hospital stay duration were recorded on designed proforma. Univariate analyses were performed to assess the rates of leaks as outcomes in form of frequency and percentage. Continuous measures (e.g., age) were summarized in means \pm S.D.

\section{Results}

A total 102 consecutive patients underwent open primary hand sewn gastro intestinal anastomosis, Among them 18 patients were withdrawn for missing in following-up and remaining 102 patients met inclusion criteria were subjected in this cross sectional study, as summarized in table 1.

The results showed that, out of 102 patients underwent open primary hand sewn gastro intestinal anastomosis, 16 were found with anastomotic leak, assuming a frequency of $15.6 \%$. Among these 16 patients having anatomic leak, $11(11 \%)$ are male \& $5(5 \%)$ are female. Among these 16 patients having anatomic leak, 13 patients developed leaks on first week of surgery during hospitalization where 03 patients developed in 10 days during follow-up. The length of hospital stay, re-admission and incisional hernia were higher in patients who developed anastomotic leak. In this study, among 61 patients who underwent gastro intestinal 
anastomosis in emergency operation developed leaks in 10 patients, having frequency of $16.3 \%$ and remaining 41 $(40 \%)$ patients of underwent operations electively developed leaks in 06 patients, having frequency of $14.6 \%$.

\section{Discussion}

Anastomotic leak is one of the most dangerous complications having as negative outcomes with prolonged hospital stay, morbidity mortality and the difficult management which puts higher burden on health care system.-6

In this regard numerous techniques and tools have been developed for monitoring and preventing this complication, but none seems to influence the course of outcomes, so for so, still medical literature does not submit any single randomized controlled trial to compare and evaluate the efficacious procedures for good out comes as delineated by Dietil M and colleagues. $^{14}$

This study is attempted to report on the outcomes in gastrointestinal anastomosis and has found the increase rates (16.3\%) patients with anastomotic leaks, who underwent in emergency operation in comparison to rates $(14.6 \%)$ who underwent for operations electively, this may be as they were prepared and optimized pre-operatively for surgery and this is in same line as described by Bruce and colleagues ${ }^{15}$. Although overall leak rate $(15.6 \%)$ in this study is sum of various sites of surgeries but is strikingly higher in comparison to other studies. ${ }^{16-22} \mathrm{We}$ observed that patients having anastomotic leaks had increased operative times and greater intra-operative blood loss in comparison to non-leaked patients. This intra-operative observation is also seen in literature as the reasons for anastomotic leak. $^{23}$

The duration of hospitalization, Re-operation for fecal diversions, drainage of collections, incisional hernia and resource expenditure for management were higher in the patients having leaks, and these findings are corresponding with other studies in literature. ${ }^{3,4,24}$ In this study, five (5\%) patients were died, three patients from anastomotic leak were died in hospital within 25 days, remaining two patients died in follow-up and were without anastomotic leaks. However anastomotic leak related mortality in literature looks to be higher as in most of studies anastomoses are seen in colorectal cancers. ${ }^{6,23}$ While our study have patients of different diseases with different sites of anastomosis. The lower mortality rate in this study is may be due to small sample size and short follow-up.

\section{Conclusions}

Anastomotic leak following gastrointestinal anastomosis is less complication in this study. Further studies are requested with large data and more follow ups to ensure the findings of this study at national level. In gastro intestinal anastomosis, prompt diagnosis, evaluation of patients, proper pre-operative optimization and skillful intervention can reduce the rates of this dreadful complication of anastomotic leak. 


\section{References}

1. Bruce J, Krukowski ZH, Al-Khairy G, Russell EM, Park KG. Systematic review of the definition and measurement of anastomotic leak after gastrointestinal surgery. British Journal of Surgery, 2001; 88 (9): 1157-68.

2. Van Daele E, Ceelen W, Van Nieuwenhove Y, Pattyn P. Risk factors and consequences of anastomotic leakage after Ivor Lewis oesophagectomy. Interactive cardiovascular and thoracic surgery, 2015; 276.

3. Mäkelä JT, Kiviniemi H, Laitinen S. Risk factors for anastomotic leakage after left-sided colorectal resection with rectal anastomosis. Diseases of the colon \& rectum, 2003; 46 (5): 653-60.

4. Karanjia ND, Corder AP, Bearn P, Heald RJ. Leakage from stapled low anastomosis after total mesorectal excision for carcinoma of the rectum. British Journal of Surgery, 1994; 81 (8): 1224-6.

5. Golub R, Golub RW, Cantu Jr R, Stein HD. A multivariate analysis of factors contributing to leakage of intestinal anastomoses. Journal of the American College of Surgeons, 1997; 184 (4): 364-72.

6. Walker KG, Bell SW, Rickard MJ, Mehanna D, Dent OF, Chapuis PH, Bokey EL. Anastomotic leakage is predictive of diminished survival after potentially curative resection for colorectal cancer. Annals of surgery, 2004; 240 (2): 255-9.

7. Dakwar A, Assalia A, Khamaysi I, Kluger Y, Mahajna A. Late complication of laparoscopic sleeve gastrectomy. Case reports in gastrointestinal medicine, 2013; 2013.

8. Guo J, Chu X, Liu Y, Zhou N, Ma Y, Liang C. Choice of therapeutic strategies in intrathoracic anastomotic leak following esophagectomy. World journal of surgical oncology, 2014; 12 (1): 402.

9. Gonzalez R, Sarr MG, Smith CD, Baghai M, Kendrick M, Szomstein S, Rosenthal R, Murr MM. Diagnosis and contemporary management of anastomotic leaks after gastric bypass for obesity. Journal of the American College of Surgeons, 2007; 204 (1): 47-55.

10. Docherty JG, McGregor JR, Akyol AM, Murray GD, Galloway DJ. Comparison of manually constructed and stapled anastomoses in colorectal surgery. West of Scotland and Highland Anastomosis Study Group. Annals of surgery, 1995; 221 (2): 176.

11. Romero RV, Goh KL. Esophageal perforation: Continuing challenge to treatment. Gastrointestinal Intervention, 2013; 2 (1): 1-6.

12. Licht E, Markowitz AJ, Bains MS, Gerdes H, Ludwig E, Mendelsohn RB, et al. Endoscopic management of esophageal anastomotic leaks after surgery for malignant disease. The Annals of thoracic surgery, 2016; 101 (1): 301-4.

13. Vonlanthen R, Slankamenac K, Breitenstein S, Puhan
MA, Muller MK, Hahnloser D, et al. The impact of complications on costs of major surgical procedures: a cost analysis of 1200 patients. Annals of surgery, 2011; 254 (6): 907-13.

14. Deitel M, Crosby RD, Gagner M. The first international consensus summit for sleeve gastrectomy (SG), New York City, October 25-27, 2007. Obesity surgery, 2008; 18 (5): 487-96.

15. Bruce J, Krukowski ZH, Al-Khairy G, Russell EM, Park KG. Systematic review of the definition and measurement of anastomotic leak after gastrointestinal surgery. British Journal of Surgery, 2001; 88 (9): 1157-68.

16. Eckmann C, Kujath P, Schiedeck TH, Shekarriz H, Bruch HP. Anastomotic leakage following low anterior resection: results of a standardized diagnostic and therapeutic approach. International journal of colorectal disease, $2004 ; 19$ (2): 128-33.

17. Yeh CY, Changchien CR, Wang JY, Chen JS, Chen $\mathrm{HH}$, Chiang JM, Tang R. Pelvic drainage and other risk factors for leakage after elective anterior resection in rectal cancer patients: a prospective study of 978 patients. Annals of surgery, 2005; 241 (1): 9-13.

18. Hyman N, Manchester TL, Osler T, Burns B, Cataldo PA. Anastomotic leaks after intestinal anastomosis: it's later than you think. Annals of surgery, 2007; 245 (2): 254-8.

19. Pickleman J, Watson W, Cunningham J, Fisher SG, Gamelli R. The failed gastrointestinal anastomosis: an inevitable catastrophe? Journal of the American College of Surgeons, 1999; 188 (5): 473-82.

20. Choy PY, Bissett IP, Docherty JG, Parry BR, Merrie A, Fitzgerald A. Stapled versus handsewn methods for ileocolic anastomoses. The Cochrane Library, 2011.

21. Alves A, Panis Y, Trancart D, Regimbeau JM, Pocard M, Valleur P. Factors associated with clinically significant anastomotic leakage after large bowel resection: multivariate analysis of 707 patients. World journal of surgery, 2002; 26 (4): 499-502.

22. Vignali A, Fazio VW, Lavery IC, Milsom JW, Church JM, Hull TL, et al. Factors associated with the occurrence of leaks in stapled rectal anastomoses: a review of 1,014 patients. Journal of the American College of Surgeons, 1997; 185 (2): 105-13.

23. Walker KG, Bell SW, Rickard MJ, Mehanna D, Dent $\mathrm{OF}$, Chapuis $\mathrm{PH}$, et al. Anastomotic leakage is predictive of diminished survival after potentially curative resection for colorectal cancer. Annals of surgery, 2004; 240 (2): 255-9.

24. McMillan DC, McArdle CS, Morrison DS. A clinical risk score to predict 3-, 5-and 10-year survival in patients undergoing surgery for Dukes B colorectal cancer. British journal of cancer, 2010; 103 (7): 970-4. 